\title{
EDUCATION AND TRAINING Women speakers in healthcare: speaking up for balanced gender representation
}

\author{
Authors: Rose Penfold, ${ }^{A}$ Katie Knight, ${ }^{B}$ Nada Al-Hadithy, ${ }^{C}$ Lucia Magee ${ }^{D}$ and Greta McLachlan ${ }^{\mathrm{E}}$
}

\begin{abstract}
Women comprise the majority of the UK's health and social care workforce, yet remain underrepresented in senior leadership positions. This is reflected in the balance of speakers, chairs and panels convened for healthcare conferences, with disproportionate gender balance. Accumulating evidence suggests that greater diversity across multiple characteristics, including gender, improves staff experience, organisational performance and patient outcomes. Conferences provide opportunities for inclusivity and new ideas only when attendees feel empowered to speak up. If we are to increase diversity of our current leadership, aspiring leaders need to see relatable role models. This article explores the issue of 'manels' and male-dominated speaker lineups, offering practical suggestions for conference organisers, women speakers and male allies to address the issue. We also outline the background to 'Women Speakers in Healthcare': a grassroots initiative founded by a team of aspiring leaders, which aims to achieve balanced gender representation at all healthcare conferences and events.
\end{abstract}

KEYWORDS: Conference, gender equality, healthcare workforce, women, gender balance

\section{Introduction}

We regret that the conference organisers couldn't find a suitable female speaker for the panel...

Women comprise the majority of the health and social care workforce in the UK, yet occupy approximately $41 \%$ of seats on NHS organisational boards and remain significantly underrepresented in senior leadership positions across the sector. ${ }^{1}$ Given this, when trying to convene high-profile speakers for a health and social care conference, it is highly probable that conference organisers may find themselves with relatively few women on the stage, or even in the precarious position of convening a 'manel' - a term coined to describe an all-male

Authors: Aacademic clinical fellow, Guy's and St Thomas' NHS Foundation Trust, London, UK; ${ }^{\text {B }}$ paediatric emergency medicine consultant, North Middlesex University Hospital, London, UK;

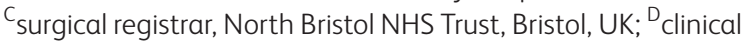
fellow, NHS Improvement, London, UK; E Editorial registrar and clinical fellow, British Medical Journal, London, UK panel of speakers (Fig 1). Conferences offer key opportunities to showcase diversity and inclusivity, to network, share ideas and best practice and as leverage points for effecting cultural and organisational change. It is the authors' belief that to rebalance the persisting gender imbalance, conference organisers and attendees, women speakers and male allies need to actively raise awareness of the issue, identify and address the specific challenges facing women and provide a platform from which speakers can have their voices heard. We all have a collective responsibility to end any excuse that event organisers wanted more women to speak - but either couldn't find anyone suitable to invite, or that invited speakers were unable to attend.

\section{Comment}

When I was president of the Royal College of Physicians (RCP), one of my personal aims was to increase the diversity of the organisation. As only the third woman president in 500 years, it seemed an obvious area to focus on. The RCP Council approved a report led by Prof Dame Parveen Kumar, exploring the diversity in the college and making recommendations on how to improve it. We were able to change the status quo relatively easily by raising awareness of the imbalance, and encouraging colleagues from more diverse background to stand for election, and apply for college roles. I am proud of the organisation for the progress made during my term of office, and of the women and black, Asian and minority ethnic physicians in leadership roles. The college officers and RCP Council now reflect the membership much more accurately, but there is still work to be done. This year's conference, Medicine 2019 was a wonderful celebration of a wide range physicians from across the world working together and remembering that \#medicineisbrilliant. This paper highlights that there is still work to be done to promote gender equality in the medical profession, and to encourage all physicians to take part in conferences as speakers, and as panellists. Healthcare delivery is struggling all over the world, and so now, more than ever, we must benefit from the qualities that we all bring, whatever our background, and whatever our gender. Diversity in the clinical workplace, and at conferences, enhances care, improves the educational experience and needs to be encouraged. Please take note of the advice provided in this article, and help us redress the balance.

Prof Dame Jane Dacre

(Prof Dame Jane Dacre is leading the government's independent review of the gender pay gap in medicine.) 


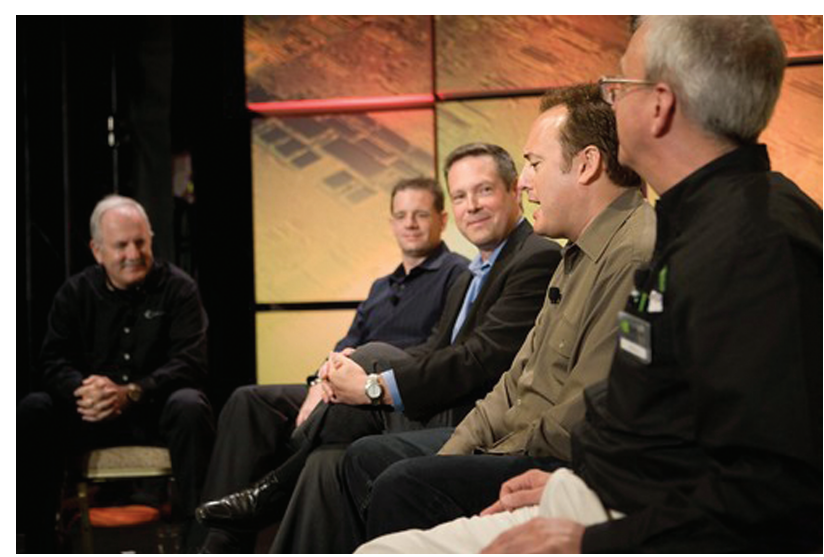

Fig 1. A 'manel' or all-male panel. Reproduced with permission from Creative Commons. Emerging Companies Summit panel. NVIDIA Corporation, 2009. Licensed under CC BY-NC-ND 2.0.

\section{Disparity and diversity in the NHS}

Gender-based disparities remain within the health and social care workforce in relation to multiple indicators. Identifying and addressing these is high on the national agenda. An interim update published in March 2019 from the independent review of the gender pay gap in medicine demonstrated an overall NHS gender pay gap of $23 \%$ in favour of men, with a $17 \%$ gender pay gap for doctors based on total pay. ${ }^{2}$ This interim report indicated that women remain underrepresented in senior medical grades, while they are overrepresented in lower-paid specialties. Women are also disproportionately underrepresented in higher managerial and leadership positions across healthcare. In an attempt to address this, in 2017 NHS Improvement and NHS Employers committed to a target of 50:50 gender representation on NHS organisational boards by 2020 and outlined a series of recommendations to help organisations achieve this (Fig 2). ${ }^{1}$ At the time, the proportion of female-held seats across 452 boards

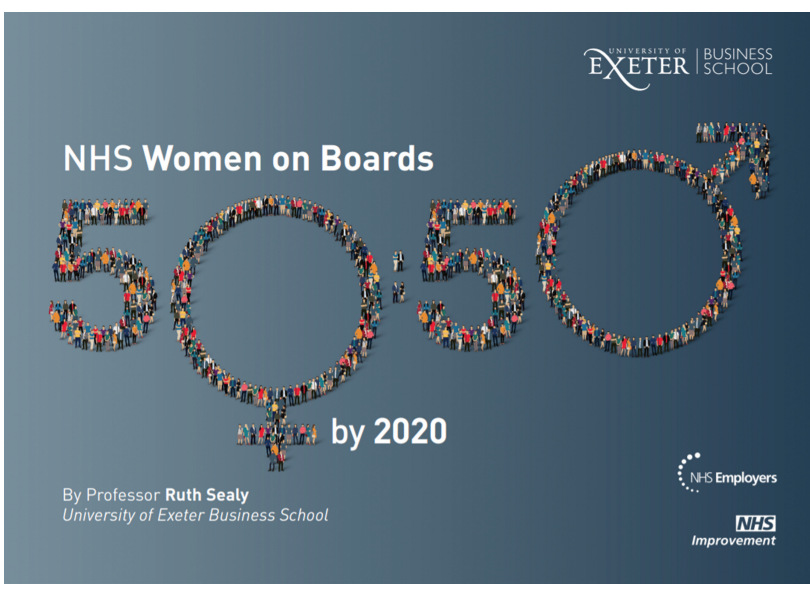

Fig 2. A national commitment to 50:50 gender representation on NHS organisational boards. Cover of report. Sealy R. NHS Women on Boards by 2020. NHS, 2017. ${ }^{1}$ was $41.0 \%$; achievement of the 50:50 target will therefore require a further 500 women on boards by next year, an average of one woman per board.

Why is this so important? Because diversity in all forms has been shown to improve decision making by teams and deliver better outcomes. ${ }^{3}$ Diversity brings fresh perspectives, broader experience and new ideas to solving complex problems. But changing the status quo is not easy. Women face additional career challenges and gender-specific barriers to attaining leadership roles, ultimately resulting in a cumulative disadvantage to career progression. ${ }^{4} \mathrm{NHS}$ leaders have expressed concerns that women are still treated differently in the workplace and continue to experience negative unconscious biases and even active discrimination. ${ }^{5}$ Until the sources of this discrimination are appropriately identified and corrected, meaningful progress towards gender equality in healthcare will be significantly hindered.

Given this, it is perhaps unsurprising that organisers trying to convene well-known names as chairs, speakers or panellists for their conference or event often find themselves with a genderunbalanced lineup. We found global - although not UK-specific evidence to support this. A recent cross-sectional analysis in the US and Canada demonstrated that the mean proportion of female speakers across 181 medical conferences was 34.1\%; although this represents an increase from $24.6 \%$ in 2007 , paralleling the increase in female physicians over the same time period, women continue to be significantly underrepresented. ${ }^{6}$ Mainstream and social media have been quick to highlight notable examples of gender imbalance, including via dedicated Twitter accounts (including, for example, @manelwatchUS and @manelwatchuk). Followers of these channels expressed indignation over many recent events, including Jamat-e-Islami's male-dominated women's empowerment conference in Pakistan and the all-male panel 'joining efforts for breast-feeding' in Mexico City. Earlier this year, a new law proposed in the state of Alabama, which makes abortion a crime at any stage of pregnancy, was passed by an almost exclusively white, male US Senate. Since these issues affect primarily women and indeed the whole of society, it would seem just that women have a proportional number of seats at the table to debate them.

From an initial state of gender predominance, a selfperpetuating cycle ensues. Event organisers, for reasons of ease and availability, implicitly favour speakers with a previous track record of speaking engagements. As things stand, the majority of these are men.

\section{We need to talk about 'manels'...}

Conferences and panels provide a platform to share experiences and perspectives. When you limit the range of perspectives, you limit the quality of the conversation. - Simon Rothery, chief executive officer, Goldman Sachs Australia ${ }^{7}$

What is the issue with this, assuming that these male speakers and 'manels' have the prerequisite experience and expertise for the topic? Firstly, a panel is convened at a healthcare conference to ensure a diversity of opinions and perspectives are brought to key issues affecting health and social care. There are many reasons why this goal may not be achieved - most obviously, because of a failure to assemble a diverse panel in the first place. Speakers and panels should model what we want our healthcare 
system and organisations to look like. Greater diversity in the health and social care workforce has been shown to yield practical benefits, including a culturally competent workforce, improved access to high-quality care for the medically underserved and enhanced patient care and experience. ${ }^{8}$ Furthermore, if we are to increase the diversity of our current leadership, emerging and aspiring clinical leaders need positive role models that they can relate to. Sealy and Singh argue that the scarcity of female role models in leadership positions plays a major part in the persistence of the gender stereotypical construction of leadership. ${ }^{9}$ An absence of women on the stage perpetuates an absence of women at the event - when the majority of speakers are male, fewer female audience members choose to (and are chosen to) speak, reducing the diversity of views and new ideas brought to the discussion. While the focus of this article is on gender, we would suggest that the same argument holds for other forms of diversity including, for example, race and ethnicity, sexual orientation and disability.

\section{Deeds not words}

It is not enough for the NHS merely to continue to champion the idea of inclusion and diversity. - Interim NHS People Plan ${ }^{10}$

To truly address gender imbalance, we need to actively promote women speakers and raise their profile so that they are positioned to lead the change. There are numerous examples from medicine and other fields where decisive steps have been taken to increase gender diversity, with positive impact. In 2011, chief medical officer, Dame Sally Davies mandated that academics will not receive funding from the National Institute of Health Research unless their organisation has achieved at least the Silver Award of the Athena SWAN Charter for Women in Science. ${ }^{11}$ Early evidence suggests that linking government funding to Athena SWAN status in this way has led to important structural and cultural changes for women in research. ${ }^{12} \mathrm{~A}$ McKinsey report published in 2015 found that for every $10 \%$ increase in gender diversity, earnings rose by $3.5 \%{ }^{13}$ Indeed, in some corporate institutions, chief executives are paid based on their diversity and inclusion data at each managerial level. Furthermore, the same report showed that senior leadership teams with more diversity (by gender and ethnicity) and an inclusive culture outperform other teams with less diversity. It is the authors' belief that similarly decisive action should be taken to increase gender diversity at healthcare conferences and events - and can lead to similar positive impact.

Here, we have collated a few of the actions that peers and senior colleagues have suggested that conference organisers, attendees, women speakers and male allies can take. It should be emphasised that the overall aim is for gender balance - not token female representation (Fig 3).

\section{Conference organisers}

$>$ Be mindful of the panel and speakers you are convening. Seek out and encourage women with relevant knowledge and experience to step forward.

$>$ Engage early with speakers, allowing sufficient notice for leave or childcare arrangements.

> Be flexible with the agenda to accommodate speakers' other commitments, for example childcare.

$>$ Women and men speakers must be offered equal speaker fees.

$>$ Childcare costs should be appropriately reimbursed as an expense or, if not possible, consider crèche facilities at the event.

> If you can, offer or signpost appropriate coaching opportunities for more inexperienced speakers.

> Offer positive and constructive feedback and praise to female speakers at events.

> Where majority-male lineups do occur, openly acknowledge this and outline steps being taken to avoid this as a future occurrence.

\section{Conference attendees}

> Be cognisant of 'manels' and unbalanced speaker lineups. Highlight to organisers and the wider community where these occur.

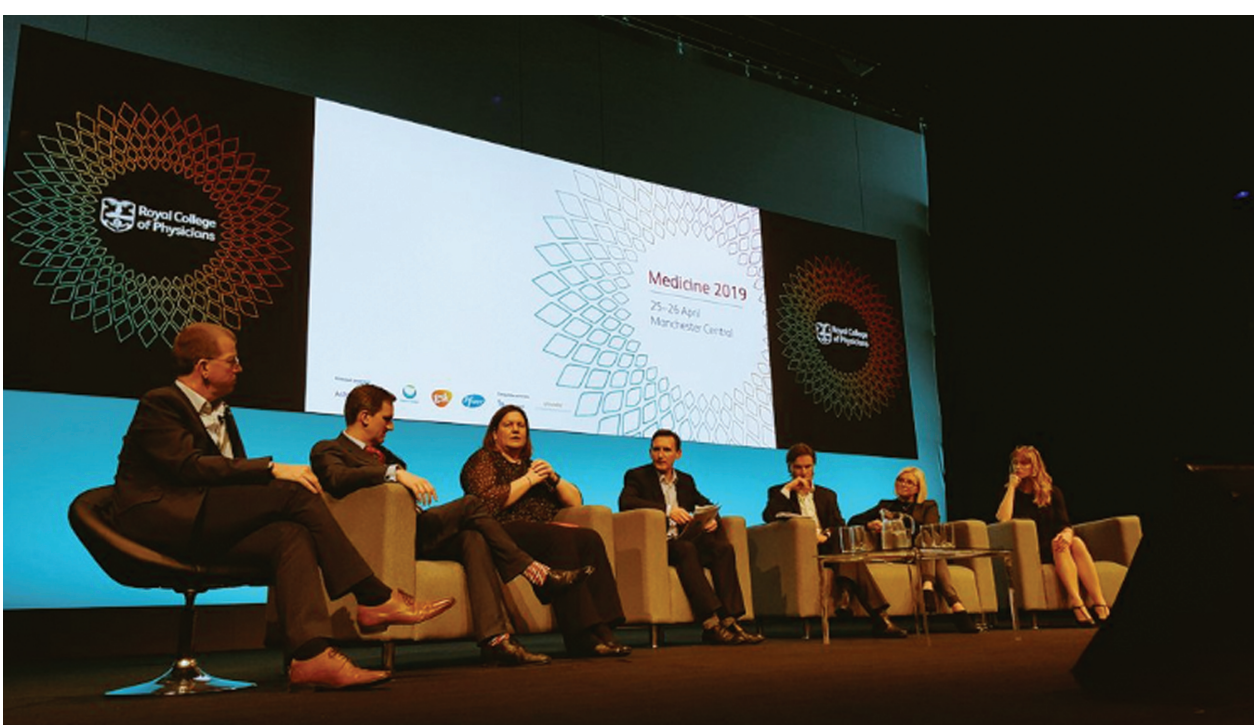

Fig 3. A gender-balanced expert panel on digital health and artificial intelligence at the Royal College of Physicians Medicine 2019 Conference, April 2019. Reproduced with permission. 
Fig 4. Women Speakers in Healthcare: aiming to achieve balanced gender representation at all healthcare conferences and events. Screenshot of website reproduced with permission. ${ }^{16}$

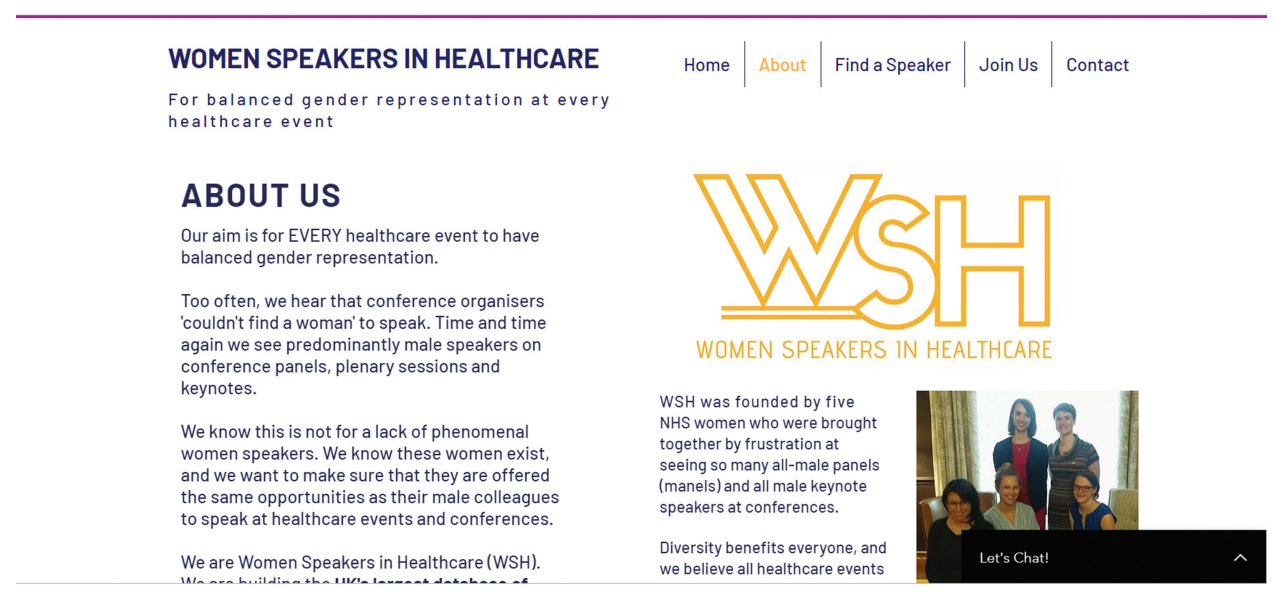

> Speak up, draw on your own experiences to challenge the views of the panel or speaker.

> Where there is one woman on a panel, ensure that the chair does not permit male speakers to speak over her.

> Offer positive and constructive feedback and praise to female speakers at events.

> Be aware that women presenters who have negative experiences are less likely to speak again.

\section{Women speakers}

$>$ Women need to support each other's successes and to 'lift as they climb'.

> As a speaker, consider coaching and a formal or informal mentor.

> Think about a mentee, to work together towards your respective goals.

> Prompt conference organisers about your external commitments, childcare costs etc.

$>$ Be authentic and honest about the challenges of balancing work and personal commitments.

> Overcome self-doubt: reframe the 'no'.

$>$ Make sure your voice is heard on mixed-gender panels.

\section{Male allies}

Achieving gender equality requires the engagement of women and men, girls and boys. It is everyone's responsibility. - Ban Ki-Moon, former secretary-general of the United Nations. ${ }^{14}$

> Gender parity will not be achieved without male support.

> The recent 'Men as allies' report identified several key actions men can take, including encouraging different models of working, challenging gender-based assumptions and offering women support for their personal development. ${ }^{15}$

> Encourage male speakers to see change as positive rather than threatening.

> Recognise that not all men will embrace or understand the drive for balanced gender representation and try to support those that don't.

> Make a stand and take 'The pledge', signed and popularised by male leaders across sectors - At a public conference I won't serve on a panel of two people or more unless there is at least one woman on the panel, not including the chair. ${ }^{10}$

\section{Women Speakers in Healthcare}

Inspired to drive the change, we founded Women Speakers in Healthcare (WSH), with the aim to achieve balanced gender representation at all healthcare conferences and events (Fig 4). ${ }^{16}$ Women are invited both to self-nominate and to nominate other speakers to join a central database of speakers. Conference and event organisers can contact WSH to enquire about their event; we identify appropriate speakers from the database and connect the conference organiser with relevant speaker(s). This grassroots initiative has gained extensive publicity via a dedicated website, ${ }^{16}$ social media channels and personal networks and has garnered widespread support from both female and male leaders across the NHS. Since the initiative was launched in April 2019, there have been 410 speaker signups, including healthcare professionals, patients and carers from a diversity of backgrounds, and multiple speaker requests. WSH has had significant social media impact, with 1,820 followers and 23,800 impressions on Twitter in the most recent 28 day period (at time of writing). We have several longer-term aims: as well as continuing to build the speaker database and facilitate organiser-speaker connections, we intend to evaluate the connections made and the experiences of women speakers attending events. We wish to explore any barriers and issues identified and to work with speakers and allies to generate solutions. Never again do we want to hear the words 'We regret that the conference organisers couldn't find a suitable female speaker for the panel...'

\section{Conclusion}

Women are critical to the delivery of health and social care in the UK, yet remain significantly underrepresented in senior leadership and managerial positions across the NHS - an imbalance which is mirrored in the chairs, speakers and panels convened for healthcare conferences and events. Redressing this imbalance is critical if we are to increase the diversity of views, opinions and experiences brought to the discussion, improve the experiences of our healthcare staff and ultimately deliver better care to patients. However, changing the status quo is not comfortable or straightforward. It requires a concerted and united effort from conference organisers, attendees, women speakers and male allies to highlight ongoing gender-based disparities and empower women to speak up and have their voices heard. Women Speakers 
in Healthcare is currently collating the largest database of women speakers in health and social care in the UK and working directly with conference organisers and presenters to facilitate speaking opportunities for women. We invite you to join us as we strive towards balanced gender representation at all health care conferences and events by publicising the initiative, joining our database and supporting others to do so. In this way, we can achieve balanced, diverse and inclusive speaker lineups which represent the wider leadership and workforce we want to see in our NHS.

\section{References}

1 Sealy R. NHS Women on Boards by 2020. NHS, 2017. www. nhsemployers.org/-/media/Employers/Publications/NHS-Womenon-Boards-report.pdf [Accessed 30 March 2019].

2 Department of Health and Social Care. New data on gender pay gap in medicine. DoHSC, 2019. www.gov.uk/government/news/ new-data-on-gender-pay-gap-in-medicine [Accessed 28 May 2019].

3 Larson E. New research: Diversity + Inclusion $=$ Better decision making at work. Forbes, 2017. www.forbes.com/sites/ eriklarson/2017/09/21/new-research-diversity-inclusion-betterdecision-making-at-work/\#38fc2b9c4cbf [Accessed 3 June 2019].

4 Newman P. NHS women in leadership: plan for action. NHS Confederation, 2015. www.nhsemployers.org/-/media/Employers/ Publications/NHS-Women-in-leadership_Br1322_WEB.pdf [Accessed 28 May 2019].

5 Rimmer A. Do we still need to tackle discrimination against women in medicine? BMJ 2017;357:j1759.

6 Ruzycki SM, Fletcher S, Earp M, Bharwani A, Lithgow KC. Trends in the proportion of female speakers at medical conferences in the United States and in Canada, 2007 to 2017. JAMA Netw Open 2019:2:e192103

7 NHS. Interim NHS People Plan. NHS, 2019.

8 Cohen J], Gabriel BA, Terrell C. The case for diversity in the health care workforce. Health Aff (Millwood) 2002;21:90-102.
9 Sealy R, Singh V. The importance of role models in the development of leaders' professional identities. In: James KT, Collins ] (eds), Leadership perspectives. London: Palgrave Macmillan, 2008.

10 Male Champions of Change. Accelerating the advancement of women in leadership: Listening, Learning, Leading. Australian Human Rights Commission, 2013.

11 Athena SWAN Charter. Advance HE, 2019. www.ecu.ac.uk/equalitycharters/athena-swan.

12 Ovseiko PV, Chapple A, Edmunds LD, Ziebland S. Advancing gender equality through the Athena SWAN Charter for Women in Science: an exploratory study of women's and men's perceptions. Health Res Policy Syst 2017;15:12.

13 Hunt V, Layton D, Prince S. Why diversity matters. McKinsey and Company, 2015. www.mckinsey.com/ /media/McKinsey/ Business \% 20Functions/Organization/Our \% 20Insights/Why \% 20 diversity \% 20matters/Why \% 20diversity \% 20matters.ashx [Accessed 3 June 2019].

14 Ban KM. Secretary-General's remarks to closing session of high-level event of the General Assembly 'The contributions of women, the young and civil society to the post-2015 development agenda'. UN, 2014. www.un.org/sg/en/content/sg/statement/2014-03-07/secretary-generals-remarks-closing-session-highlevel-event-general.

15 Men as Allies. Health Care Women Leaders Network. NHS Employers, 2019. www.nhsemployers.org/-/media/Employers/ Publications/women-leaders/Men-as-allies-report-March-2019-webfinal.pdf [Accessed 3 June 2019].

16 Women Speakers in Healthcare, 2019. www.womenspeakersinhealthcare.co.uk.

Address for correspondence: Dr Rose Penfold, Guy's and St Thomas' NHS Foundation Trust, Westminster Bridge Road, London SE1 7EH, UK.

Email: rose.penfold1@nhs.net 